DUNAMIS (Jurnal Teologi dan Pendidikan Kristiani)

Volume 2, Nomor 1 (Oktober 2017)

ISSN 2541-3937 (print), 2541-3945 (online)

http://www.sttintheos.ac.id/e-journal/index.php/dunamis

Submitted: 13 September 2017

Accepted: 31 Oktober 2017

Published: 31 Oktober 2017

\title{
Bahasa Lidah dalam Ibadah Bersama Berdasarkan I Korintus 14
}

\author{
Murni Hermawaty Sitanggang \\ Dosen Pendidikan Agama Kristen Universitas Jember \\ murni_hermawaty@yahoo.co
}

\begin{abstract}
Speaking in tongues in the chruch service together has become a controversy for a long time. Some considered it as a positive thing because of its special gift. Otherwise, many views of its contemporary as negatively, doubted it as from God. This article is a literature research with a qualitative approach using an exposition methode on 1 Corinthians 14. The aim of this research is to show clearly Pauline conception of speaking in to tongue amid the church service teogether. The conclusion is that speaking in tongue must be followed by a gift of interpreting, in order to edify people. Thus, the gift shall be useful amid God's church.
\end{abstract}

Keywords: 1 Corinthians; 14; Paul; speaking in tongues

\begin{abstract}
Abstrak
Penggunaan bahasa lidah dalam ibadah bersama telah lama menjadi sesuatu yang menimbulkan pro dan kontra. Ada yang menganggapnya sebagai sesuatu hal positif sebab dianggap sebagai salah satu dari karunia rohani yang istimewa. Akan tetapi, tidak sedikit yang memandang negatif karena meragukan bahasa lidah kontemporer memang berasal dari Tuhan. Artikel ini merupakan penelitian literatur dengan pendekatan kualitatif yang menggunakan metode eksposisi pada 1 Korintus 14. Tujuannya, untuk menunjukkan konsep Paulus tentang bahasa lidah dalam ibadah bersama sesuai dengan teks 1 Korintus 14 . Kesimpulannya, bahasa lidah dalam ibadah bersama haruslah diikuti dengan karunia menafsirkan bahasa lidah, agar jemaat dapat dibangun. Dengan demikian karunia dapat berfungsi dalam gereja Tuhan.
\end{abstract}

Kata kunci: bahasa lidah; 1 Korintus 14; Paulus 


\section{PENDAHULUAN}

Bahasa lidah merupakan salah satu karunia rohani yang telah menjadi fenomena di dalam kehidupan spiritual Kristen. Fenomena ini telah dihubungkan dengan hampir semua gerakan kebangkitan dalam gereja Kristen, termasuk di dalamnya gerakan pembaharuan kharismatik. Bersama dengan karunia menafsirkannya, karunia bahasa lidah tergolong sebagai karunia yang memiliki dampak, baik dalam hal "menyatukan" maupun "memisahkan" umat kristiani pada abad ini. Oleh karena penggunaan bahasa lidah dalam ibadah tidak sedikit friksi berujung pada perpecahan; ada yang menganggapnya sebagi tanda, dan sebaliknya melihatnya sekadar karunia semata.

Selain friksi di dalam tubuh para penganut Pentakostalisme dan Karismatik, respon terhadap keberadaan bahasa lidah juga muncul dari kelompok Kristen lainnya, seperti mainstream dan Injili atau Reformed. Sebagian kalangan memberi respons positif terhadap bahasa lidah sebab mereka percaya ini merupakan salah satu karunia rohani yang meningkatkan gereja sebagai tubuh Kristus. Akan tetapi, ada juga kelompok yang menolak bahasa lidah dan menganggapnya sebagai sesuatu yang negatif. Ada anggapan bahasa lidah yang

\footnotetext{
${ }^{1}$ Russel F. Proctor II, "The Rhetorical Functions of Christian Glossolalia," Journal of Psychology and Christianity Vol.9, no. 3 (1990).
}

dimulai pada peristiwa Pentakosta di Yerusalem telah berhenti pada waktu yang lampau, sehingga apa yang terjadi pada saat ini diragukan sebagai sesuatu yang berasal dari Tuhan. ${ }^{2}$ Namun hal ini pun tidak sepenuhnya dapat diterima, karena pandangan yang dibangun lebih bersifat curiga dan sentimentil denominasi.

Persoalan bahasa lidah di zaman ini pada umumnya sering mengacu pada penyelidikan biblikal 1 Korintus 12-14, khususnya pada pasal 14 . Selain membahas tentang karunia Roh Kudus yang berjumlah sembilan, bagian ini memberi perhatian pada masalah yang dihadapi gereja Korintus, yakni fenomena bahasa roh. Dalam surat ini diindikasikan tentang bahasa lidah yang sering digunakan oleh jemaat Korintus dan beberapa ekses negatif yang kemudian berkembang sebagai konsekuensinya, seperti adanya jemaat yang mengutuki Yesus ketika ia berbahasa lidah (1Kor. 12:3). Paulus harus menjawab pertanyaan yang timbul dari fenomena bahasa lidah dalam jemaat Korintus sebab pada saat itu bahasa lidah menjadi kontroversi sebagaimana juga yang terjadi pada saat ini di dalam tubuh Kristus. Itu

\footnotetext{
${ }^{2}$ Evan Siahaan, "MEMAHAMI PENTAKOSTALISME MELALUI BINGKAI HISTORIOGRAFI LUKAS DALAM KISAH PARA RASUL," Jurnal Antusias 4, no. 7 (June 12, 2015): 60-81, accessed October 29, 2017, http://www.sttintheos.ac.id/ejournal/index.php/antusias/article/view/6/5.
} 
sebabnya melalui tulisan ini, penulis akan mengulas berbagai pandangan tentang bahasa lidah, baik dari sisi teologi maupun dari sisi psikologi serta bagaimana sebenarnya pandangan Alkitab tentang hal ini menurut 1 Korintus 14 untuk kemudian menarik aplikasi dan kesimpulan tentang pokok ini di masa sekarang.

\section{Bahasa Lidah dalam Sejarah}

Bahasa lidah atau bahasa roh yang dalam bahasa Yunaninya menggunakan istilah glossolalia, berasal dari dua kata Yunani, glossa (lidah) dan lalein (berbicara). Ada tiga definisi dasar yang diberikan untuk kata glossa, yakni: 1) mengacu pada lidah yang hanya dianggap sebagai suatu organ untuk berbicara (Luk. 16:24); 2) dikarenakan suatu translasi nonliteral dari 1 Korintus 12:10, glossa telah dipahami sebagai suatu ucapan-ucapan yang bersifat ekstasi (ecstatic utterances); 3) menghubungkan glossolalia dengan berbicara suatu bahasa. ${ }^{3}$ Tampaknya definisi kedua merupakan definisi yang cukup populer, di mana Mallone berpendapat, dengan menerjemahkan glossa sebagai "ecstasy" sebenarnya merupakan gambaran yang keliru, yang bukan hanya terjadi pada hari Pentakosta dan di gereja Korintus, melainkan juga terjadi pada saat ini. Penafsiran yang keliru ini kemudian memicu studi yang mengaitkan glossolalia dengan schizophrenia dan histeria, di mana seseorang yang mengalami hipnotis dapat mengeluarkan gejala-gejala yang mirip dengan mereka yang ber-glossolalia.

Di dalam Alkitab sendiri bahasa lidah ditulis untuk pertama kalinya dalam peristiwa Pentakosta dalam Kisah Para Rasul 2. Pada saat itu orang percaya berkumpul di satu tempat di sebuah rumah di Yerusalem. Lalu tiba-tiba ada suara datang dari langit, seperti tiupan angin keras dan memenuhi seluruh rumah, di mana mereka duduk. Tampaklah kepada mereka seperti lidah-lidah api, yang hinggap pada mereka masing-masing. Semua mereka kemudian dipenuhi oleh Roh Kudus dan mulai berbicara dengan bahasa-bahasa lain, seperti yang diberikan oleh Roh kepada mereka untuk diucapkan (Kis. 2:1-4). Bahasa lidah kemudian disebutkan kembali dalam peristiwa pertobatan Kornelius (Kis. 10:44-46). Ia dan seisi rumahnya dipenuhi oleh Roh Kudus dan mereka berkata-kata dalam bahasa roh memuliakan Allah sementara Petrus berkotbah kepada mereka. Orangorang percaya di Efesus dalam Kisah Para Rasul 19:5-6 juga dituliskan dalam Alkitab telah mendapat pengalaman berbahasa lidah dan bernubuat.

\footnotetext{
${ }^{3}$ George Mallone, Those Controversial Gifts (Illinois: InterVarsity, 1995), 79-80. 
Dalam kehidupan gerejawi kemudian, bahasa lidah perlahan terlupakan. Tulisan kristiani antara tahun 90-150 AD secara umum berpusat seputar kehidupan internal dan tidak menyinggung soal bahasa lidah. ${ }^{4}$ Ignatius dari Antiokhia, penasihat post-New Testament yang pertama dari pelayananan Karismatik mengklaim telah berbicara di bawah efusi Roh Kudus, tetapi ia tidak menyebut tentang bahasa lidah. Kelompok Kristen pertama yang tepatnya memberi tempat istimewa untuk ecstatic speech adalah Montanis, tetapi mereka kemudian dianggap sebagai bidat karena doktrin mereka. Doktrin Roh Kudus memang kembali ditekankan pada era reformasi, namun tidak memberi penekanan khusus terhadap pentingnya bahasa lidah dalam kehidupan orang percaya.

Bahasa lidah kemudian menjadi populer di tahun 1900-an oleh gerakan Pentakostalisme. Gerakan ini berawal dari gerakan kesucian (Holiness) yang menekankan pada Second Blessing, yakni penyucian atau berdiamnya Roh yang menyebabkan pengalaman emosional dan menghasilkan suatu kehidupan yang "suci." Pada tahun 1900, Charles Parham dianggap sebagai perintis Pantekostalisme ketika satu dari muridnya di Bethel Bible

\footnotetext{
${ }^{4}$ Hugh Wamble, "Glossolalia in Christian History," in Tongues, ed. Luther B. Dyer (Missouri: Le Roi, 1971), 24.

${ }^{5}$ Ibid, 40.
}

College Topeka, Kansas, menerima Roh Kudus dan berbicara dalam bahasa lidah setelah Parham meletakkan tangan atasnya. Gerakan Pantekosta dengan bahasa lidah kemudian menjadi populer dengan peristiwa di Azusa Street di bawah pimpinan William J. Seymour. Ia menekankan kesembuhan ilahi dan baptisan Roh Kudus sebagai suatu karunia yang dicurahkan kepada orang-orang yang disucikan dan ditandai dengan glossolalia.

Gerakan bahasa lidah ini kemudian menyebar dan tidak hanya digunakan oleh kaum Pantekosta saja, tapi juga mulai dialami oleh denominasi lain. Maka kemudian lahirlah gerakan NeoPantekostalisme yang disebut juga "New Penetration," "Spiritual Renewal" dan "Charismatic Revival." 6 Gerakan ini memperoleh banyak sekali pengikut baru.

Neo-Pentakostalisme langsung menguasai orang-orang percaya yang mengalami kegelisahan, mencari dimensi spiritual yang tak mereka temukan dalam gereja mereka, namun telah diajarkan pada mereka untuk dinantikan. Mereka percaya glossolalia sebagai ledakan spontan dari Roh Kudus. Dalam pertumbuhannya kemudian, gerakan Neo- Pentakostalisme ini dianggap mulai "berlebihan" ketika mereka terlalu menekankan "iman semata" sebagai kualifikasi yang memadai untuk

\footnotetext{
${ }^{6}$ Ibid, 46 .
} 
menerima Roh Kudus dan mengabaikan kekudusan. Mereka menoleransi perilaku "kedagingan" dengan menggunakan silabelsilabel yang "berisik" sebagai "pemompa" atau "bantuan" untuk berbahasa lidah selain menggunakan teknik bernafas sebagai bantuan agar Roh Kudus "menghembusi" mereka. Mereka menodai bahasa lidah dengan menggunakannya di depan publik dan eksperimen ilmiah dengan mengklaimnya sebagai suatu kuasa untuk memberikan karunia Roh Kudus seakanakan manusia dapat membagi-bagikan karunia-karunia Roh, padahal hanya Roh Kudus yang dapat memiliki kuasa dalam hal ini. Mereka bahkan menganggap bahasa lidah sebagai suatu fenomena yang dapat dipahami secara psikologi dan tidak secara spiritual. $^{7}$

\section{Berbagai Pandangan Teologi Kontemporer Tentang Bahasa Lidah}

Ada beberapa pandangan teologi berkaitan dengan bahasa lidah. Secara garis besar dibedakan menjadi dua; pandangan positif dan negatif terhadap bahasa lidah.

\section{Pandangan Positif}

Pertama, bahasa lidah dipandang sebagai esensi penting dalam kehidupan orang percaya yang menandainya apakah ia orang Kristen sejati atau tidak. Secara umum pandangan ini dipegang oleh

${ }^{7}$ Ibid, 51 .

49 Copyright@ 2017, DUNAMIS, ISSN 2541-3937 (print), 2541-3945 (online) golongan Karismatik, yang kemudian mendapat perlawanan dari mereka yang tidak berbahasa lidah, yang tidak menganggapnya sebagai esensi penting dalam kehidupan orang percaya.

Kedua, bahasa lidah sebagai tanda baptisan Roh, yang juga dikenal sebagai Second Blessing. Pengalaman berbahasa lidah dan teologi yang berhubungan dengan "baptisan Roh Kudus" merebak di kalangan umat Kristiani dengan intensitas yang belum pernah terjadi dalam sejarah gereja. ${ }^{8}$ Kelaparan spiritual dalam hati banyak orang ditengarai sebagai penyebab terjadinya kegerakan bahasa lidah yang luar biasa yang melanda hampir semua denominasi gereja saat ia muncul. ${ }^{9}$ Orang-orang menjadi lapar akan pengalaman langsung dengan Tuhan sehingga mereka takjub ketika sesuatu terjadi dalam hidup mereka, yang dapat mereka lihat dan rasakan. Hal ini kemudian menjadi bukti bagi mereka bahwa Allah hadir dan berkuasa dalam hidup mereka. Bila diperhatikan secara saksama, banyak orang yang mengalami perubahan hidup yang diperlihatkan dari karakter moral yang positif dan dedikasi yang luar biasa dalam pelayanan setelah mengalami pengalaman bahasa lidah. Bagi mereka dan orang-orang

\footnotetext{
${ }^{8}$ Wayne E. Ward, "Various Views of Tongue Speaking," in Tongues, ed. Luther B. Dyer (Missouri: Le Roi, 1971), 11.

${ }^{9}$ Ibid.
} 
di sekitar mereka, ini merupakan keajaiban atau mukjizat.

Gordon D. Fee kemudian mendaftarkan beberapa aspek positif lainnya dari bahasa lidah, yakni: 1) memampukan untuk memuji Tuhan dengan cara yang melampaui kata-kata manusiawi biasa, 2) menyediakan sumber kekuatan yang terus-menerus dan sukacita dalam kehidupan Kristiani, 3) memperkaya kehidupan doa dalam cara yang belum pernah terjadi sebelumnya. 10 Ia memformulasikannya sebagai berikut: "kita berdoa dalam bahasa lidah dalam posisi kelemahan karena kita tidak tahu bagaimana seharusnya kita berdoa.” Pada waktu seperti itu, ketika kita sangat membutuhkan Roh Kudus untuk membantu kita, maka Roh berdoa melalui kita apa yang sesuai dengan rencana Allah. Berdoa dalam Roh menjadi jalan yang melaluinya kekuatan Allah disempurnakan dalam kelemahan kita; ini merupakan kekuatan fundamental bagi orang percaya. ${ }^{11}$ Jadi, dengan berdoa dalam Roh dari kelemahan kita, secara implisit mempercayakan bahwa

\footnotetext{
${ }^{10}$ Gordon Fee, "PANDANGAN TEOLOGIA PAULUS TENTANG GLOSSOLALIA," Jurnal Pelita Zaman Vol.11, no. 1 (1996), http://alkitab.sabda.org/resource.php?topic $=651 \&$ res $=$ jpz.

${ }^{11}$ Daniel Sutoyo, “ALLAH MEMANGGIL UMAT-NYA UNTUK MENJADI GEREJA YANG TEKUN BERDOA MENURUT KISAH PARA RASUL 4: 23 - 31," DUNAMIS ( Jurnal Teologi dan Pendidikan Kristiani ) Vol.1, no. 1 (2016): 52-73, http://www.sttintheos.ac.id/ejournal/index.php/dunamis.
}

Roh akan berdoa sesuai dengan rencana Allah. Doa seperti ini memiliki arti adanya kebebasan dan kekuatan Allah, bukan kekuatan kita, yang kemudian menyempurnakan kelemahan kita. ${ }^{12}$

\section{Pandangan Negatif}

Pertama, sebagaimana yang sempat disinggung pada bagian awal, bahasa lidah kerap dianggap identik dengan kata-kata "ekstatik" (ecstatic utterance), yang dapat ditemukan di berbagai bentuk ritual penyembahan okultisme dimana semua pelakunya tidak menyadari apa yang ia ucapkan. Oleh sebab itu, bahasa lidah dianggap bukan bahasa sesungguhnya dan tidak lebih dari sekadar ocehan yang teratur. ${ }^{13}$ Pandangan ini menghubungkan bahasa lidah dengan fenomena klasik masa lampau dengan paralelnya di masa kini.

D. Matthew Allen berpendapat pada dasarnya praktik bahasa lidah masa kini berakar pada Montanisme, kegerakan nubuat yang berkembang pada masa gereja mula-mula, yang menekankan ecstatic utterance dalam nubuatnya. ${ }^{14}$ Gereja

\footnotetext{
${ }^{12}$ Ibid.

${ }^{13}$ Luke Timothy Johnson, "Glossolalia and the Embarrassments of Experience," The Princeton Seminary Bulletin Vol. 18, no. 2 (1997), accessed October 29, 2017, http://journals.ptsem.edu/id/PSB1997182/dmd004. ${ }^{14}$ Matthew Allen, "Excited Utterances: A Historical Perspective On Prophesy, Tongues and Other Manifestations of Spiritual Ecstasy," accessed May 26, 2017, https://bible.org/article/excitedutterances-historical-perspective-prophesy-tonguesand-other-manifestations-spiritual.
} 
ortodoks pada masa itu menganggap apa yang dilakukan oleh Montanus dan pengikutnya sebagai pekerjaan Setan dan menegaskan bahwa mukjizat tertinggi adalah pertobatan, bukan ekstasi yang irasional yang lebih mengarah kepada kesombongan pribadi. ${ }^{15}$

Kedua, bahasa lidah dinyatakan sebagai karunia terakhir yang disebutkan Paulus dalam pasal 12. Pada Roma 12 dan Efesus 4 bahkan tidak disebut sama sekali, memberi kesan pada kita ia bukan karunia yang signifikan dibandingkan karunia lainnya. J. Hurt and Steve Rudd berasumsi alasan mengapa Paulus menempatkannya di akhir dalam 1 Korintus 12:28 karena kemungkinannya untuk membangun sangat terbatas, kecuali dalam pekerjaan penginjilan di garis misi. ${ }^{16}$ Jadi, pada dasarnya bahasa lidah dianggap sekedar karunia pelengkap saja alias "tidak penting."

Ketiga, bahasa lidah telah berhenti. Ronald E. Baxter menghubungkan kehancuran Yerusalem pada tahun 70 AD oleh Jenderal Titus menandai berhentinya bahasa lidah, terlebih lagi kanon Kitab Suci pun telah ditutup. ${ }^{17}$ Tidak ada lagi

\footnotetext{
${ }^{15}$ Ibid.

16“'Speaking in Tongues," accessed August 26, 2017 , http://www.rapidnet.com/ jbeard/bdm/Psychology/ch ar/speaking.htm.

${ }^{17}$ Ronald E. Baxter, Charismatic Gift of Tongue (Grand Rapids: Kregel, 1985), 68.
}

pewahyuan diberikan lewat nubuat atau pengetahuan. Semuanya telah berhenti. Ia bahkan menaksir periode berhentinya bahasa lidah antara 70-100 AD. Menurutnya, Paulus menulis 1 Korintus 1214 sekitar tahun 55 AD di mana bahasa lidah masih memiliki tujuan sebagai suatu tanda kepada bangsa Yahudi bahwa nubuatan Yesaya sedang digenapi. Namun demikian, setelah kejatuhan Yerusalem dan sebelum penyelesaian Kitab Suci, karunia bahasa lidah telah berhenti, tak pernah didengar lagi dari bibir gereja yang dewasa (1Kor. 13:11). Kesimpulan yang dapat ditarik dalam hal ini adalah bahasa lidah dipandang bukanlah untuk gereja masa kini karena bahasa tersebut telah berhenti.

Keempat, sebagian dari mereka yang berbahasa lidah mungkin kerasukan setan. ${ }^{18}$ Dasar dari pandangan ini adanya kemiripan prilaku antara pelaku bahasa lidah dengan mereka yang berada di bawah medium spiritisme. Penglihatan, efek fisik (lengan dan tubuh yang berguncang) disebabkan oleh kontrol supranatural adalah sama pada keduanya. Seringkali orang-orang yang berbahasa lidah memberi gambaran seakan mereka seperti berada di bawah suatu kuasa saat mengalaminya. ${ }^{19}$

\footnotetext{
${ }^{18}$ Richard C. Schwab, Let The Bible Speak About Tongues (Grand Rapids: Kregel, 1985), 104105.

${ }^{19}$ Robert G. Gromacki, The Modern Tongues Movement (Grand Rapids: Baker Book, 1967), 40.
} 51 Copyright@ 2017, DUNAMIS, ISSN 2541-3937 (print), 2541-3945 (online) 
Kelima, bahasa lidah disebabkan oleh kondisi psikologis, seperti: ${ }^{20}$ 1) karena ekstasi, yang berarti dalam kondisi emosional yang sangat tinggi, orang tersebut kehilangan akal sehatnya dan mengeluarkan kata-kata yang bersemangat; 2) karena auto-hypnosis, maksudnya adalah ada suatu perasaan frustasi dan konflik di dalam, terutama orang Kristen yang merasa kurang puas dengan pengalaman mereka dan mencari "rahasia" hidup berkelimpahan; 3) kemungkinan adalah prilaku yang dipelajari. 4) Hanyalah buatan yang dibuat sendiri oleh si pelaku, mengulang suara-suara dasar yang disugestikan kepadanya. ${ }^{21}$

\section{METODOLOGI}

Metode yang digunakan dalam penelitian ini adalah metode eksposisi surat 1 Korintus 14. Metode ini digunakan untuk menjelaskan secara gamblang persoalan yang dihadapi oleh jemaat Korintus dan menganalisisnya berkaitan dengan fenomena serupa yang terjadi pada gereja masa kini. Penulis menggunakan metode deskriptif untuk menjelaskan sejarah perkembangan bahasa lidah dalam sejarah gereja hingga menjadi fenomena yang mendunia.

\section{ANALISIS DAN \\ HASIL PEMBAHASAN}

Setelah membahas mengenai dua pandangan berbeda terhadap bahasa lidah, kini saatnya untuk melihat bagaimana pendapat Alkitab mengenai hal ini. Paulus membahas tentang bahasa lidah dalam suratnya kepada jemaat Korintus kemungkinan disebabkan ada beberapa masalah yang timbul akibat karunia ini di kalangan jemaat.

\section{Pentingnya Komunikasi yang Jelas dalam Ibadah Bersama (ay. 1-19)}

Paulus memulai 1 Korintus 14 dengan anjuran untuk mengejar kasih (ay. 1). Dari sini kita dapat melihat relasi antara pasal 14 dengan pasal sebelumnya yang menekankan tentang kasih. Mengejar kasih dan mengaplikasikannya adalah hal terpenting yang tak dapat diabaikan, bahkan kita harus menjadikannya prioritas utama. Tetapi Paulus juga mendorong orang percaya untuk mengharapkan karuniakarunia rohani, terutama nubuat. Hal ini terlihat dari pemakaian tiga kata kerja ("kejarlah," "usahakanlah," dan "terutama karunia bernubuat") dalam ayat pembuka 1 Korintus 14 yang kesemuanya dalam bentuk sekarang (present tense) untuk mengindikasikan agar pembaca selalu berusaha mematuhi perintah tersebut. ${ }^{22}$

\footnotetext{
${ }^{22}$ Simon Kistemaker, I Corinthians (Grand Rapids: Baker Books, 1994), 46.
}

${ }^{20}$ Ibid. 
Maksud Paulus dengan mengedepankan nubuat adalah karena ia ingin membandingkannya dengan bahasa lidah, yang tampaknya cukup populer di kalangan jemaat Korintus saat itu. Jemaat di sana mencampurkan antara Roh Kudus dengan antusiasme. Mereka merasa terlihat lebih saleh ketika mereka berbahasa lidah. Oleh sebab itu, Paulus kemudian mengingatkan mereka agar berhati-hati dalam hal ini mengingat kuasa misterius yang juga bekerja dalam dalam kehidupan penyembahan berhala mereka sebelum mengenal Tuhan (12:2). Satu hal penting yang dapat membuktikan karunia bahasa lidah sebagai karya dari Roh Allah adalah apapun yang dikatakan maupun dilakukannya serta memproklamirkan Ketuhanan Yesus (12:3), bukan mempertunjukkan kecakapan religius seseorang. Pesan yang diucapkan dalam bahasa lidah tanpa interpretasi tidaklah diarahkan kepada manusia, tetapi kepada Allah sebab tidak seorang pun kecuali Allah dapat mengerti apa yang dikatakan. Sementara bagi yang lain semua yang dikatakan orang tersebut adalah suatu misteri. $^{23}$ Itu sebabnya, Paulus kemudian menekankan kepada jemaat Korintus bahwa dalam ibadah bersama, komunikasi yang

\footnotetext{
${ }^{23}$ Anthony C. Thiselton, The First Epistle to the Corinthians (Grand Rapids: CNIGTC, 2000), 1085.
}

jelas dan dapat dimengerti oleh semua pihak adalah lebih penting. ${ }^{24}$

Seseorang yang berbahasa lidah tanpa diterjemahkan berarti ia hanya berhubungan dengan Tuhan dan tidak memberi pengaruh kuat yang positif bagi yang lain, sedangkan orang yang bernubuat memberi pesan kepada jemaat, yang memiliki tiga tujuan: membangun, membesarkan hati dan menghiburkan orang percaya. ${ }^{25}$ Seseorang yang bernubuat, ucapannya membangun jiwa orang percaya dengan membangkitkan semangat dan menghiburkan duka citanya. Pada dasarnya hal esensial yang menjadi sasaran dari pelayanan tidak lain dari penghiburan, kebahagiaan, atau bahkan keselamatan dari setiap individu yang mengambil bagian di dalamnya.

Bahasa lidah bukanlah sesuatu yang terlarang bagi orang percaya (ay.5). Namun nubuat memiliki nilai lebih, bukan dalam hal keabsolutannya dan bukan dalam standar moralnya, melainkan lebih dalam hal keluasan dan kedalaman manfaatnya di mana semua orang dapat memahami dan dibangunkan olehnya. Itu sebabnya Paulus mendorong mereka yang berkata-kata dengan bahasa roh untuk dapat memberi penjelasan atau menafsirkannya sehingga

\footnotetext{
${ }^{24}$ Keith Krell, "Prophets Are Up (1 Corinthians 14:1-25)," accessed August 26, 2017 , https://bible.org/seriespage/29-prophets-are-1corinthians-141-25.

${ }^{25}$ Kistemaker, I Corinthians, 478.
} 
orang lain dapat memahami dan dibangunkan olehnya.

Paulus dengan jelas menyatakan bahwa persekutuan ibadah menjadi sia-sia bila kita tidak dapat saling membangun. Ia kemudian mengumpamakan jika ia datang kepada jemaat Korintus dengan berbahasa roh, bahasa rohnya akan sia-sia bila jemaat Korintus tidak memahaminya. Lebih berguna jika ia berbicara kepada mereka tentang pewahyuan yang ia terima dalam bentuk khotbah atau pengajaran (ay. 6).

Paulus menguatkan argumennya dengan memberikan ilustrasi di ayat 7-9 yang daripadanya kita dapat menyimpulkan: bahasa lidah atau bahasa roh, sama halnya dengan musik yang harus dapat dikenali oleh pendengarnya, juga haruslah dapat dikenali oleh yang lain juga. Sama seperti seruling atau kecapi tak akan dipahami kecuali mereka menghasilkan perbedaan dalam bunyinya, begitu jugalah bahasa lidah tak dapat dimengerti oleh orang lain sebab tidak mengucapkan katakata yang mudah dimengerti. Orang menggunakan bahasa untuk membuat komunikasi lebih mudah. Ada banyak bahasa di dunia ini dan tiap-tiapnya punya arti. Akan tetapi komunikasi hanya dapat terjadi dengan baik jika tiap bagian menggunakan bahasa yang dapat dipahami yang lain (ay. 10-12).
Agar dapat membangun gereja, bahasa lidah tersebut haruslah diikuti dengan penafsirannya. Yang perlu digarisbawahi di sini adalah bila seseorang berbahasa roh dalam ibadah bersama, Paulus ingin setiap orang memperoleh manfaat dari pesan yang disampaikan. ${ }^{26}$ Jadi, bila ada seseorang yang berbahasa lidah yang tak dimengerti, seharusnya disertai dengan penafsiran. Penafsiran tersebut dapat berasal dari orang lain atau orang yang berbahasa lidah tersebut (ay. 13).

Paulus sebenarnya juga memiliki karunia bahasa roh dan ia menggunakannya juga, namun dalam ibadah pribadinya (ay. 19). Ia tidak ragu-ragu untuk menunjukkan apresiasinya tentang bahasa roh. Alasan mengapa Paulus mengungkapkan informasi pribadinya ini adalah untuk mendorong jemaat Korintus mengikuti teladannya dalam mengelola karunianya untuk membangun jemaat. ${ }^{27}$ Fee meyakini pertanyaan krusial di sini bukanlah apakah seseorang berbahasa roh atau tidak, tetapi apa yang sepatutnya dikerjakan dalam ibadah bersama. ${ }^{28}$ Ayat 19 menyiratkan bahwa Paulus sedang membedakan antara ibadah pribadi dengan ibadah bersama

\footnotetext{
${ }^{26}$ Evan Siahaan, "REFLEKSI ALKITABIAH FENOMENA GLOSSOLALIA,” Jurnal Antusias Vol. 2, no. 1 (January 2012): 160-179, accessed September 29, 2017, http://www.sttintheos.ac.id/ejournal/index.php/antusias/article/view/67/66.

${ }^{27}$ Ibid.

${ }^{28}$ Gordon Fee, The First Epistle to Corinthians (Grand Rapids: Eerdmans, 1988), 675.
} 
(pertemuan jemaat). Ia lebih memilih "lima kata yang dapat dimengerti" dari pada "beribu-ribu kata dengan bahasa roh" sebab hanya bahasa yang mendidik yang memiliki kesempatan "membangun" yang lain. Paulus juga menggunakan frasa "lima kata yang dapat dimengerti" untuk menunjukkan bahwa yang ia maksudkan adalah bahasa yang diketahui, yang dipakai bersama sehari-hari. Karena gereja adalah tempat dimana umat Tuhan dibangun melalui pengajaran dan pemberitaan firman Tuhan dan kemudian setelah itu dikuatkan dalam iman, maka berbicara dengan bahasa roh yang tidak ditafsirkan tidak berkontribusi apa-apa dalam membangun jemaat.

\section{Perlunya Kedewasaan Berpikir di dalam Gereja (ay. 20-25)}

Paulus kemudian menegur jemaat Korintus karena mereka secara terusmenerus mendemonstrasikan cara kekanakkanakan dalam pemikiran mereka (ay. 20). Sebagian dari mereka mungkin memamerkan karunia lidah mereka dan meremehkan mereka yang tidak memilikinya sehingga Paulus perlu menekankan kedewasaan mereka. Jika seseorang lebih tertarik dalam mempertontonkan kebolehannya dari pada saling membangun dengan yang lain, itu berarti ia bertindak kekanak-kanakan. Lagi pula penggunaan bahasa lidah yang mereka terapkan dalam ibadah mereka menjadikan penyembahan mereka menjadi berpusat pada pribadi (self-centered worship) dan tentu saja ini tidak dapat dibenarkan.

Mengenai problema yang terdapat dalam ayat 22 bahwa bahasa roh adalah tanda bagi orang tak beriman, Fee memiliki suatu gagasan bahwa Paulus pada dasarnya hendak menyatakan bahwa karena bahasa lidah tidak dapat dipahami, orang yang tidak beriman tidak menerima wahyu dari Allah sehingga mereka tetap tidak percaya. $^{29}$ Hampir senada dengan Fee, Kistemaker kemudian menyimpulkan bahwa bagi orang yang tidak percaya, yang mengeraskan hatinya dan menolak injil, bahasa lidah serta nubut menjadi tandatanda penghakiman, yang akan menghakimi mereka yang tidak percaya. ${ }^{30}$

Penekanan yang berlebihan seharusnya tidak ditempatkan pada bahasa lidah, bahkan di kalangan orang percaya sebab penggunaan yang berlebihan dari karunia ini akan memiliki efek merugikan bagi orang-orang luar yang tidak memahaminya dan mereka akan berpikir orang-orang percaya telah kehilangan akal sehat (ay. 23). ${ }^{31}$ Paulus meminta jemaat Korintus agar memakai karunia tersebut dengan cara

\footnotetext{
${ }^{29}$ Siahaan, "REFLEKSI ALKITABIAH FENOMENA GLOSSOLALIA."

${ }^{30}$ Kistemaker, I Corinthians, 501.

${ }^{31}$ Kenneth L. Barker and John Kohlenberger III, NIV Bible Commentary (Grand Rapid: Zondervan, 1994), 646.
} 
yang dewasa agar jemaat tidak terpecah oleh karenanya.

\section{Aturan dalam Ibadah Bersama (ay. 26-40)}

Dalam tafsirannya, Matthew Henry menyatakan Paulus menyalahkan jemaat yang membawa kebingungan ke dalam ibadah dengan memamerkan karunianya sehingga sama sekali tidak membangun jemaat. ${ }^{32}$ Paulus menegaskan bahwa setiap karunia, baik bahasa roh maupun nubuat, yang digunakan dalam ibadah bersama, harus dilakukan dengan tertib (ay. 26-33a). Apabila di dalam jemaat ada yang berbahasa roh dan bernubuat, hanya dua atau tiga orang yang boleh berbicara, jangan terlampau banyak agar tidak timbul kebingungan. Bila seseorang berbahasa roh, harus ada yang menafsirkan. Bila tidak, hendaklah ia berdiam diri (ay. 28).

Demikian pula ketika ada yang bernubuat, maka haruslah bergantian dan ditanggapi oleh yang lain. Aturan yang penting lainnya adalah nubuat tersebut haruslah sesuai dengan Alkitab. Jika ada pesan, baik melalui khotbah dan pengajaran maupun melalui kata-kata spontan, yang bertentangan dengan isi Alkitab, maka itu tidak berasal dari Tuhan. ${ }^{33}$ Jemaat yang mendengar nubuatan tersebut haruslah

\footnotetext{
${ }^{32}$ Matthew Henry, Matthew Henry's Commentary on the Whole Bible (New York: Fleming H. Revell, n.d.), 582.

${ }^{33}$ Kistemaker, I Corinthians, 508.
}

kemudian menilai kesesuaian kata-kata yang diucapkan dengan firman Tuhan.

Prinsip yang hendak ditekankan Paulus pada dasarnya adalah setiap karunia rohani haruslah membangun tubuh Kristus sehingga ia mengizinkannya dalam pertemuan ibadah dengan beberapa syarat: didasari oleh kasih, membangun dan dilakukan dengan tertib. ${ }^{34}$ Ibadah bersama bukanlah tempat untuk meninggikan diri sendiri dengan mempertontonkan kebolehan dalam menggunakan karunia rohani yang memukau, melainkan tempat untuk saling mendorong dan menguatkan satu sama lain.

\section{KESIMPULAN}

Dari pembahasan mengenai bahasa lidah menurut 1 Korintus 14 ini, dapat disimpulkan beberapa hal: Pertama, tampak jelas Paulus mencoba untuk mengoreksi penyalahgunaan bahasa lidah di antara jemaat Korintus. Hal ini didasarkan pada beberapa kiasan dari istilah yang jemaat Korintus atau Paulus gunakan, serta tingkah laku yang serupa dalam penyembahan selain penggunaan instrumen yang sama. Aspek-aspek dari bekas pemujaan berhala ini yang tampaknya Paulus hadapi dalam 1 Korintus 14:36-38. Jemaat Korintus adalah jemaat yang berorientasi kepada pengalaman dan diri sendiri. Mereka

\footnotetext{
${ }^{34}$ Ibid.
} 
dulunya adalah penyembah berhala dan ketika mereka kemudian bertobat dan menjadi pemeluk agama Kristen, mereka bingung membedakan antara pekerjaan Roh Kudus dengan pengalaman ekstasi yang pernah mereka praktikkan saat masih menjadi pemeluk paganisme. Artinya, pada fase ini Paulus sedang memerangi praktik yang keliru dari bahasa lidah.

Kedua, terlepas dari berbagai kasus yang terjadi seputar praktek bahasa lidah jemaat Korintus, Paulus ingin agar karunia bahsa lidah dapat digunakan untuk membangun $(12: 10 ; 14: 26)$. Pandangan dasar Paulus adalah positif mengenai bahasa lidah meski ia juga menegaskan bahasa lidah tidak dapat membangun gereja jika tidak ditafsirkan. Sama seperti karunia rohani lainnya, bahasa lidah haruslah dipergunakan untuk membangun tubuh Kristus. Untuk dapat memenuhi aspek membangun tersebut, bahasa lidah haruslah mengumandangkan pesan yang dapat dimengerti semua orang. Oleh sebab itu, penggunaan bahasa lidah bila hanya memperdengarkan kata-kata yang tidak membangun karena tidak dapat dimengerti oleh jemaat tidak dianjurkan dalam ibadah bersama.

\section{REKOMENDASI}

Setelah membahas bahasa lidah menurut 1 Korintus maka pertanyaannya sekarang: bagaimana sikap kita terhadap bahasa lidah kontemporer? Pertama, hindari langsung menghakimi orang yang berbahasa lidah sebab dari perspektif psikologi, mereka menyampaikan pesan tentang partisipan dan kebutuhannya. ${ }^{35}$ Kita tak dapat mengenyampingkan fakta bahwa mereka yang berbahasa lidah bersaksi hidup mereka telah diubahkan. Walau bukan pendukung gerakan bahasa roh, Gromacki mengaku bahwa sebagian orang yang dikaruniai bahasa lidah mengalami kemajuan pertumbuhan rohani yang pesat, yang ditandai dengan meningkatnya minat beribadah, mengembalikan perpuluhan, dan dalam bersaksi. Pengalaman berbahasa lidah membuat mereka lebih leluasa dalam menyembah Tuhan walau mereka kadang tidak memahami apa yang mereka ucapkan sendiri. Namun, yang paling luar biasa adalah keyakinan akan karya penebusan Allah melalui Kristus yang tampak jelas dalam hidup mereka.

Kegerakan bahasa lidah kontemporer seharusnyalah mengindikasikan kepada gereja masa kini perlunya partisipasi jemaat yang lebih dinamis dalam pelayanan penyembahan. Gereja perlu merestrukturisasikan ibadahnya untuk memberi ruang terhadap hal ini sehingga

\footnotetext{
${ }^{35}$ John Newport, "Understanding, Evaluating and Learning from the Contemporary Glossolalia Movement," in Tongues (Missouri: Le Roi, 1971), 120.
} 
ibadah yang diselenggarakan dapat menjadi perkumpulan keluarga yang saling membangun dari pada sekadar perkumpulan birokrasi.

Menurut pengamatan Amos Yong, seorang teolog Pantekosta, banyak gereja telah kehilangan unsur penyembahan dan partisipasi jemaat dalam ibadahnya. ${ }^{36}$ Dalam hal inilah bahasa lidah memberi pencerahan sebab ia menyimbolkan kesatuan tubuh Kristus yang berbahagia dan suatu tanda profetik dari Tuhan bagi umatNya. Tidak jauh berbeda dengan Yong, Fee mengklaim Paulus menghargai bahasa lidah (1Kor. 14:2, 4a, 15, 17-18) sebab meski tidak dimengerti oleh yang berbicara, berdoa “di dalam Roh" seperti ini membangun orang percaya. Senada dengan Fee, Proctor berpendapat pada hakikatnya bahasa lidah merupakan sarana untuk berdoa tanpa dibatasi oleh keterbatasan manusiawi.

Kita juga harus berhati-hati dengan perpecahan yang terjadi di gereja Tuhan karena perbedaan pandangan tentang bahasa lidah. Pada dasarnya semua gereja adalah tubuh Kristus dan sudah sepatutnya bersatu, saling merangkul, dan saling membangun, bukan saling menjatuhkan karena perbedaan pandangan mengenai penggunaan karunia rohani. Tuhan

\footnotetext{
${ }^{36}$ Amos Yong, "Tongues of Fire in the Pantecostal Imagination," Journal of Pantecostal Theology April (1998).
}

menghendaki umat-Nya bersatu agar dapat melaksanakan pekerjaannya di bumi ini.

Kedua, kita harus menyadari meski Paulus tidak melarang penggunaannya dalam pertemuan jemaat, ia pun tidak mendorong melakukannya. Orang yang berbahasa lidah tidak memahami apa yang ia katakan sehingga tanpa penafsiran tidak akan berguna bagi tubuh Kristus. Paulus menegaskan bahwa umat Tuhan harus mencoba semampu mereka untuk berbicara yang dapat dipahami oleh yang lain dan mengejar karunia nubuat (1Kor. 14:1, 3-6, 9, 12, 24-25, 28). Paulus mengakui bahwa ia berbahasa lidah lebih dari semua orang Korintus (ay. 18) dan ia ingin semua orang juga demikian. Tetapi ia menegaskan bahwa di dalam gereja yang terpenting adalah saling membangun. Jadi, dalam ibadah umum, karunia yang dapat membangun gereja yang lebih sesuai. Itu sebabnya Paulus mengatakan ia lebih suka jemaat Korintus bernubuat (ay. 5). Jadi, kita dapat menyimpulkan seperti Paulus: usahakanlah dirimu untuk memperoleh karunia untuk bernubuat dan janganlah melarang orang yang berkata-kata dengan bahasa roh. Tetapi segala sesuatu harus berlangsung dengan sopan dan teratur.

Setiap orang percaya memiliki tanggung jawab untuk menggunakan karunia rohaninya bagi pembangunan tubuh Kristus. Pada dasarnya, bernubuat dan 
berbahasa lidah hanyalah dua dari sekian banyak karunia rohani yang Tuhan berikan bagi gereja-Nya. Oleh sebab itu, umat Tuhan memiliki tanggung jawab untuk mengeksplorasi karunia apa yang dimilikinya dan menggunakannya untuk kemuliaan Kristus. Yang jelas, aturan yang sama berlaku untuk semua karunia dan setiap orang, yakni segala sesuatu harus meninggikan Tuhan dan dikerjakan dengan tertib dan teratur serta tidak menyimpang dari kebenaran Alkitab yang adalah firman Tuhan. Ibadah bersama seharusnya menjadi tempat di mana umat Tuhan saling membangun. Hakikat persekutuan umat Tuhan bukanlah berpusat pada diri sendiri (self-centered) melainkan berpusat pada Kristus (Christ centered). Segala sesuatu yang sifatnya hanya membangun diri sendiri tak perlu dibawa di ibadah umum. Jadi, penggunaan bahasa lidah tanpa penafsiran sebenarnya lebih tepat digunakan pada saat ibadah pribadi daripada saat ibadah bersama.

\section{DAFTAR KEPUSTAKAAN}

Allen, Matthew. "Excited Utterances: A Historical Perspective On Prophesy, Tongues and Other Manifestations of Spiritual Ecstasy." Accessed May 26, 2017. https://bible.org/article/excitedutterances-historical-perspectiveprophesy-tongues-and-othermanifestations-spiritua.
Barker, Kenneth L., and John Kohlenberger III. NIV Bible Commentary. Grand Rapid: Zondervan, 1994.

Baxter, Ronald E. Charismatic Gift of Tongue. Grand Rapids: Kregel, 1985.

Gordon Fee. "PANDANGAN TEOLOGIA PAULUS TENTANG GLOSSOLALIA." Jurnal Pelita Zaman Vol.11, no. 1 (1996). http://alkitab.sabda.org/resource.php?t opic $=651 \&$ res $=$ jpz.

- The First Epistle to Corinthians. Grand Rapids: Eerdmans, 1988.

Gromacki, Robert G. The Modern Tongues Movement. Grand Rapids: Baker Book, 1967.

Henry, Matthew. Matthew Henry's Commentary on the Whole Bible. New York: Fleming H. Revell, n.d.

II, Russel F. Proctor. "The Rhetorical Functions of Christian Glossolalia." Journal of Psychology and Christianity Vol.9, no. 3 (1990).

John Newport. "Understanding, Evaluating and Learning from the Contemporary Glossolalia Movement.” In Tongues. Missouri: Le Roi, 1971.

Kistemaker, Simon. I Corinthians. Grand Rapids: Baker Books, 1994.

Krell, Keith. "Prophets Are Up (1 Corinthians 14:1-25)." Accessed August 26, 2017. https://bible.org/seriespage/29prophets-are-1-corinthians-141-25.

Luke Timothy Johnson. "Glossolalia and the Embarrassments of Experience." The Princeton Seminary Bulletin Vol. 18, no. 2 (1997). Accessed October 29, 2017.

http://journals.ptsem.edu/id/PSB19971 82/dmd004.

Mallone, George. Those Controversial Gifts. Illinois: InterVarsity, 1995.

Schwab, Richard C. Let The Bible Speak About Tongues. Grand Rapids: Kregel, 1985. 
Siahaan, Evan. "MEMAHAMI

PENTAKOSTALISME MELALUI

BINGKAI HISTORIOGRAFI

LUKAS DALAM KISAH PARA

RASUL." Jurnal Antusias 4, no. 7

(June 12, 2015): 60-81. Accessed

October 29, 2017.

http://www.sttintheos.ac.id/e-

journal/index.php/antusias/article/view $16 / 5$.

"REFLEKSI ALKITABIAH

FENOMENA GLOSSOLALIA."

Jurnal Antusias Vol. 2, no. 1 (January

2012): 160-179. Accessed October 29,

2017. http://www.sttintheos.ac.id/e-

journal/index.php/antusias/article/view /67/66.

Sutoyo, Daniel. “ALLAH MEMANGGIL UMAT-NYA UNTUK MENJADI GEREJA YANG TEKUN BERDOA MENURUT KISAH PARA RASUL 4: 23 - 31." DUNAMIS ( Jurnal

Teologi dan Pendidikan Kristiani)

Vol.1, no. 1 (2016): 52-73.

http://www.sttintheos.ac.id/ejournal/index.php/dunamis.

Thiselton, Anthony C. The First Epistle to the Corinthians. Grand Rapids: CNIGTC, 2000.

Wamble, Hugh. "Glossolalia in Christian History." In Tongues, edited by Luther B. Dyer. Missouri: Le Roi, 1971.

Ward, Wayne E. "Various Views of Tongue Speaking." In Tongues, edited by Luther B. Dyer. Missouri: Le Roi, 1971.

Yong, Amos. "Tongues of Fire in the Pantecostal Imagination." Journal of Pantecostal Theology April (1998).

"Speaking in Tongues." Accessed August 26, 2017.

http://www.rapidnet.com/ jbeard/bdm /Psychology/char/speaking.htm. 